\title{
GRUPOS DE ENCONTRO COM MORADORES DE RUA DA CIDADE DE JATAÍ-GO: UMA EXPERIÊNCIA PSICODRAMÁTICA
}

\section{GROUPS MEETING WITH RESIDENTS OF THE CITY OF STREET JATAÍ GO: AN EXPERIENCE PSYCHODRAMATIC}

\author{
Érico Douglas Vieira ${ }^{1}$ \\ Bárbara Maria Oliveira Assis; Denice Resende Silva; \\ Fernanda Silva de Meira;João Victor Bueno Lopes; \\ Maykon Richard Miranda de Moura;Zélia Borges Souza Rocha. ${ }^{2}$
}

RESUMO: O trabalho descreve a promoção de grupos de encontro semanais realizados durante um ano com público alvo de moradores de rua e pessoas em situação de risco social da cidade de Jataí-GO. Os encontros foram planejados adotando-se a metodologia do Psicodrama que permitiu a leitura do processo grupal bem como ferramentas técnicas para as intervenções. A natureza do trabalho é de extensão com a participação de um docente e seis discentes, tendo como um dos objetivos a aproximação dos alunos com a realidade da cidade. Outro foco adotado foi a criação de um espaço para reflexão e trocas de experiências com o foco na promoção da autonomia da população atendida. Observamos uma transformação do grupo que, no início se comportava de modo fechado e resistente. $O$ vínculo de confiança entre a equipe e o grupo foi construído e importantes trocas de experiências entre eles foram sendo tecidas. Um crescente processo de responsabilização pela própria vida foi um resultado importante observado entre os membros do grupo.

Palavras-Chave: Moradores de rua. Psicodrama. Autonomia.

ABSTRACT: The paper describes the promotion of group meetings held weekly for one year with the target audience of homeless people and social risk in the city of Jataí-GO. The meetings were designed by adopting the methodology of psychodrama that allowed the reading of the group process tools and techniques for intervention. The nature of work is an extension with the participation of one teacher and six students, taking as an approximation of the goals of the students with the reality of the city. Another focus was adopted to create a space for reflection and sharing experiences with a focus on promoting the autonomy of the population served. We observed a transformation of the group that at first he behaved so close and tough. The bond of trust between the team and the group was constructed and important exchange of experience between them have been woven. A growing process of accountability for their lives was an important result observed among group members.

Keywords: Homeless. Psychodrama. Autonomy.

\section{INTRODUÇÃO}

“Eu sustento que a finalidade da ciência é aliviar a miséria humana”. Brecht

\footnotetext{
${ }^{1}$ Psicólogo pela UFMG; Mestre em Psicologia pela PUC Minas; Professor do curso de Psicologia da UFG - Campus Jataí; E-mail: ericopsi@yahoo.com.br

${ }^{2}$ Discentes do Curso de Psicologia da UFG - Campus Jataí.
} 
O presente artigo consiste em um relato de experiência sobre um trabalho de natureza interventiva cujo público alvo consiste de população de rua e pessoas em situação de risco social da cidade de Jataí-GO. Realizaram-se intervenções com encontros semanais em grupo coordenados e planejados pelos docente e discentes que integram a equipe. Representa um trabalho de extensão com vistas a cumprir o objetivo da Universidade de servir e se aproximar da comunidade. Como objetivo principal, temos a promoção da autonomia dos usuários através do trabalho de grupo. Ainda buscamos oferecer um espaço para reflexão sobre o projeto de vida bem como facilitar a troca de experiências de maneira que um possa ser agente terapêutico do outro (MORENO, 1959). Finalmente, a promoção de um espaço para a emergência de um processo de responsabilização pela própria vida. O nosso marco teórico de referência é o Psicodrama, especialmente o conceito de espontaneidade e a metodologia de trabalho em grupo.

O presente trabalho cumpre com a expectativa de que haja uma aproximação da Universidade Federal de Goiás com a comunidade através dos projetos de extensão. Visa levar a Universidade para além de suas fronteiras, no intuito de entrar em contato com a realidade concreta e integrar a teoria com a prática. Reveste-se de importância, ainda, na medida em que coloca os estudantes frente a uma população excluída e pauperizada, na tentativa de sensibilizar os futuros profissionais para a atuação com setores da população em situações precárias.

O projeto propõe intervenções de caráter emancipatório com uma população que não recebe nenhum atendimento por parte do poder público de Jataí-GO. Não existem políticas públicas na cidade para atender a população de rua, as únicas intervenções são de caráter assistencialista de iniciativa da sociedade civil. Portanto, é importante a realização de um trabalho que almeje resgatar a autonomia de uma população excluída e assistida de maneira assistencialista.

Ainda constata-se a relevância teórica do projeto, pois existem escassos trabalhos que descrevem e refletem sobre a população de rua de pequenas cidades. Geralmente encontram-se pesquisas realizadas com moradores de rua de grandes metrópoles (VARANDA, 2004; ALVAREZ, 2004; BRITO, 2006). Como resultado, 
teremos um panorama das especificidades dos moradores de rua de uma cidade pequena de aproximadamente 87 mil habitantes, material inexistente na literatura especializada.

O objetivo principal seria a criação de um espaço para reflexão e trocas de experiências com o foco na promoção da autonomia da população atendida. O públicoalvo freqüenta a instituição Nosso Lar - Casa de Apoio e nesta recebe diariamente alimentação, cuidados básicos de higiene e saúde (corte de cabelo, banho, curativos, etc). Além disso, existe um espaço de oração e amparo religioso. A instituição é coordenada por Maides Abadia Nogueira que também é sua fundadora. O Nosso Lar conta com auxílio financeiro da Prefeitura Municipal de Jataí, doações e trabalho voluntário. No momento, doze voluntárias trabalham no Nosso Lar no preparo das refeições que são servidas diariamente de segunda a sexta-feira. A maioria dos usuários é do sexo masculino, alguns moram nas ruas, outros são os chamados "trecheiros" que percorrem trechos de uma cidade a outra em busca de oportunidades. Há ainda os que possuem casa, mas vivem em situação sócio-econômica precária. Em média, sessenta pessoas são atendidas diariamente.

\subsection{O Nosso Lar}

Após esta breve introdução, passemos a descrever a história da instituição Nosso Lar - Casa de Apoio. A idealizadora e atual dirigente da instituição é dona Maides que nos relata como teve início o seu trabalho. Ela mora em frente a uma praça localizada no centro da cidade, que é freqüentada por muitos moradores de rua. Dona Maides começou a sensibilizar-se com a situação precária em que se encontravam e passou fazer marmitas e oferecer aos moradores de rua. Durante dois anos ela obteve auxílio por meio de doações de supermercados e voluntários. Aos poucos o número de atendidos aumentou, fato que fez com os vizinhos queixassem à Prefeitura de Jataí. Dona Maides, então, pediu apoio à Prefeitura para preparar e fornecer as refeições em outro local. Uma casa foi alugada pela Prefeitura no início de 2009, necessitando de reparos e melhorias que foram feitos com o auxílio dos usuários e voluntários.

Atualmente o compromisso da Prefeitura é o pagamento do aluguel, todo o restante é obtido por meio de doações. Segundo depoimento de Dona Maides, algumas voluntárias procuram o trabalho como forma de combate à própria depressão. 


\section{OS MORADORES DE RUA}

Passemos a descrever e caracterizar os usuários da instituição. Os moradores de rua geralmente são pessoas que não têm mais documentos, não possuem trabalhos formais nem moradia fixa e também se encontram com vínculos familiares e sociais rompidos. Estas rupturas conduzem esta população a um estado de crescente degradação e vulnerabilização. Esta situação é agravada pelas atuais polarizações econômicas, a reestruturação demográfica e pelas novas dinâmicas do trabalho que criam uma situação propícia para a concentração de riqueza no mundo e particularmente no Brasil, deixando graves seqüelas sociais sem a contrapartida do Estado diante da miserabilidade crônica da população. Mesmo que no Brasil existam soluções informais e às vezes ilícitas para se enfrentar os problemas da moradia - através da ocupação de áreas de mananciais e ocupação de prédios públicos, ou ainda para enfrentar o desemprego - através do trabalho informal, como é o caso dos ambulantes, um grande número de pessoas acaba nas ruas com a ausência de políticas públicas de apoio (VARANDA, 2004).

Agora passemos a discutir a terminologia da população de rua, segundo Varanda (2004). Geralmente, estes termos são utilizados pela própria população de rua. Os maloqueiros são aqueles que dormem nas ruas, nas chamadas malocas, isto é, local onde pequenos grupos ficam durante o dia ou na noite que são compostos por colchões velhos, algum canto reservado para os pertences pessoais (roupas e documentos) e, às vezes, utensílios de cozinha. O usuário de albergue ou albergado é quem se refugia em albergues. "Trecheiro" ou andarilho é o termo vindo dos trabalhadores que transitavam de uma cidade para outra a procura de trabalho, e que continua sendo usado pejorativamente por uns e naturalmente por quem já teve a experiência de trecho. Em geral, as viagens são tipicamente padronizadas e não aleatórias. "Pardais" são os moradores de rua que se fixam e não trabalham. Os usuários de álcool são denominados de bêbado, alcoólatras ou bebuns. Na visão destes, as outras pessoas que utilizam outras drogas, como a maconha, o crack e a cocaína são os "nóias”, especificadamente os que usam crack são conhecidos pelo nome de "pedreiros". Há também os doentes mentais que sobrevivem principalmente aceitando doações, catando comida no lixo e 
mendigando. Na sua rotina de vida não incluem o uso de álcool e droga, são os mais reclusos e socialmente isolados até pelos próprios “vizinhos” de calçada.

Alvarez (2004) aponta as situações existenciais extremas a que estão submetidos os moradores de rua. Estes vivem sem proteção para os próprios corpos, expostos a violências, mendicância e embriaguez. Em um estudo realizado pela autora, com um grupo da cidade de São Paulo, percebe-se o sentimento de vergonha em face da situação em que viviam. Outro sentimento preponderante é a desconfiança na sociedade e na própria capacidade para enfrentar necessidades urgentes. A cidade possui, de um lado, o segmento dos integrados, com melhores e mais justas oportunidades. Do outro lado, os que sobrevivem às sobras do banquete dos eleitos. Estes excluídos colecionam perdas que podem os levar à criminalidade ou à drogadicção, como aponta a autora:

Muitos dos moradores de rua, os caídos pertencentes a esse segmento social de excluídos, perderam-se de si mesmos. Junto às perdas de endereços, certidões de nascimento, carteiras de identidades - símbolos de cidadania entrecruzam-se as perdas de esperança, do sentido da vida, da vontade de viver (ALVAREZ, 2004, p. 50)

Em decorrência desta situação os moradores de rua podem se envolver com a criminalidade, fato que os retira de uma situação de invisibilidade. A violência se apresenta como resposta à falta de reconhecimento social. Desta forma, passam a ser vistos na categoria de "bandido" que deve ser banido da sociedade para as prisões. Outra forma de lidar com a falta de sentido seria o consumo de álcool e drogas que representa uma busca de anestesiar a dor psíquica, mas que termina por afundar o usuário em desespero e vergonha.

Brito (2006) por outro lado, faz uma análise de que a rua não representa um espaço de solidão, sendo um espaço de organização de uma rede de camaradagem e convivência. As pessoas e grupos profundamente empobrecidos, lesados em sua dignidade e autonomia, sem os recursos básicos necessários à subsistência, utilizam a rua como espaço simbólico como afirma a autora:

A apropriação do espaço público por esses “noveaux pauvres” para o desenvolvimento de atividades de mendicância, mercantil, criativa ou moradia se fundamenta em um sistema de classificação que acaba por delimitar "arenas" cujas regras de convivência estão constantemente abertas ao debate entre eles e os concorrentes usuários desses espaços, que são os donos e trabalhadores de empresas, residentes e cidadãos que por aí transitam no cotidiano. A coexistência de usos, de interesses e atividades diversas no espaço público torna-se possível através de negociações 
recorrentes, que objetivam a construção de acordos ou consentimentos forçados (BRITO, 2006, p.322).

A vida nas ruas depende de negociações que geram regras de convivência nas quais é preciso fazer uso da força física e da criatividade para a sobrevivência.

Em relação à maneira como são vistos pela sociedade, observam-se duas reações que vão da piedade ao temor (MENDES e MACHADO, 2004). Os vizinhos e transeuntes que convivem com os moradores de rua ora enxergam estes como vítimas, que sofrem e precisam da misericórdia alheia. Neste ponto, podem originar-se ações assistencialistas em direção a população de rua, muitas vezes entremeadas por questões religiosas. Outro tipo de caracterização seria a de que o morador de rua pode ser violento, colocando o outro numa posição de medo e ameaça. O temor pode gerar ódio como forma defensiva, expondo a população de rua a humilhações e violências. Exemplo disto são os recentes ataques sofridos por moradores de rua, geralmente perpetrados por grupos de jovens de classe média alta.

Diante do exposto este trabalho de extensão teve como intuito contrapor as soluções assistencialistas na tentativa de promover um espaço para que os usuários possam refletir sobre as próprias vidas e responsabilizarem-se por elas. O intuito é que a população atendida pudesse resgatar sua dignidade e autonomia através das trocas de experiências no grupo. Como convite à responsabilização os moradores de rua são compelidos a saírem da posição de vítimas, de quem sempre precisará da ajuda dos outros.

\section{PSICODRAMA}

Pode-se dizer que temos dois pilares que sustentaram o nosso trabalho. Um deles seria a noção de autonomia, o outro seria o conceito de espontaneidade do Psicodrama. Espontaneidade é o estado produtor de todo processo criativo. Vejamos a definição de espontaneidade para Moreno, criador do Psicodrama: "É a capacidade de um indivíduo para enfrentar adequadamente cada nova situação ou dar novas respostas para situações antigas” (MORENO, 1931, p. 132). Quando Moreno refere-se à adequação da ação, ele quer dizer que o indivíduo espontâneo enfrenta novas situações utilizando-se livremente dos seus recursos - inteligência, memória, percepção, sentimentos, dentre outros - com um mínimo possível de restrições exteriores e entraves internos. Nesse caso, o indivíduo experimenta um estado de autonomia e liberdade, um livre fluxo de sentimentos, em que sua ação está em sintonia com seus sentimentos e pensamentos. 
Naffah-Neto (1997) estabelece uma revisão dos conceitos elaborados por Moreno e questiona a questão da adequação da resposta. O autor argumenta que subjaz no conceito de espontaneidade de Moreno uma relação de exterioridade do sujeito com relação à sociedade. Como o Psicodrama é uma abordagem existencialista a relação do sujeito com a sociedade não seria de oposição e sim como ser-no-mundo. Assim, espontaneidade seria uma relação de compromisso entre sujeito e mundo, num esforço de recuperação de uma presença atuante e integrante da situação. Dentro desta perspectiva, este trabalho objetivou, através da realização dos grupos de encontro, promover entre os moradores de rua a capacidade de recuperação da presença atuante e da abertura para o real. Em termos morenianos buscou-se, através das reflexões proporcionadas pelas trocas de experiências em grupo, que os usuários pudessem alcançar e desenvolver a capacidade de dar novas respostas às situações antigas.

Em vista do exposto acima, é importante salientar que temos uma visão crítica com relação aos trabalhos assistencialistas que podem manter as pessoas em um estado de indigência, como aponta Brito (2006, p. 322):

\footnotetext{
Na falta de uma política consistente, apresentam-se muitas vezes, nas ruas, os mais variados segmentos sociais caritativos, que acabam por realizar, com o desprendimento e boa vontade que lhes são próprios, a proeza de cuidar, mantendo as pessoas em um estado de indigência, humilhação e assujeitamento, alimentando um processo que poderíamos denominar institucionalização da população na rua.
}

Tanto o nosso trabalho quanto os referidos trabalhos caritativos encontram enormes barreiras e limites devido à péssima distribuição de renda no país que concentra excessivamente a renda em uma camada privilegiada da população, a inexistência de uma política governamental de geração de trabalho e a ausência de uma política digna de saúde, educação e habitação. Ademais, os trabalhos caritativos proliferam como forma de compensação a toda esta carência de políticas públicas adequadas a esta população. O grande problema é que este tipo de trabalho mantém esta população refém de uma posição de quem sempre espera a ajuda do outro. Deste modo, o morador de rua perde a oportunidade de acionar saídas singulares e autônomas para seus obstáculos.

\section{INTERVENÇÕES EM GRUPO}


A proposta divide-se em dois momentos e espaços. Temos um espaço de supervisão no qual há a reflexão em cima de artigos científicos para que se integre teoria e prática. Neste espaço são discutidos os encontros e analisadas as dificuldades e progressos na condução do grupo. Há ainda um momento no qual o próximo encontro é planejado.

A estrutura do encontro é planejada tendo-se sempre em foco os objetivos do trabalho. Utiliza-se a estrutura dentro do referencial do Psicodrama (VIEIRA, 2009). Desta forma, os encontros passam por três fases:

- O aquecimento que seria a preparação do grupo com vistas à busca de um problema em comum e do protagonista adequado. Geralmente utilizamos técnicas para estimular o corpo para atitudes e atuações espontâneas.

- A fase da ação propriamente dita. Nesta fase propomos ao grupo jogos dramáticos e exercícios de dinâmica de grupos coerentes com o tema planejado.

- O compartilhamento no qual estimulamos os membros do grupo a fazerem uma reflexão sobre a contribuição do encontro para as suas vidas.

Os temas trabalhados foram: perspectivas e sonhos para o futuro, linha da vida (acontecimentos importantes), como lido com a ansiedade, como posso dar novas respostas para antigos problemas, será que é possível reparar erros do passado, identidade, dentre outros.

Os encontros em grupo aconteceram de maio de 2009 a maio de 2010. Relataremos, a seguir, alguns resultados observados do trabalho. Os membros do grupo serão retratados somente com a inicial dos nomes como forma de garantirmos o sigilo.

Nos primeiros encontros pode-se observar que os membros do grupo estavam fechados e resistentes com relação ao trabalho. Alegavam que tinham "vergonha” em se expressar em grupo. No nosso entendimento, talvez não estivesse muito claro, até então, a nossa proposta.

Estabelecemos um contrato com eles, explicando que se trata de um trabalho de extensão da UFG, envolvendo alunos e professor. Explicamos, também, que o objetivo de desenvolver o trabalho no Nosso Lar tem ligação com um valor do grupo que é o de levar os conhecimentos da psicologia para quem não pode pagar este serviço. Parece 
que depois desta explicação o vínculo de confiança entre nós e eles começou a ser construído.

Trabalhamos, então, fazendo um levantamento sobre os temas que eles julgavam importantes para serem tratados nos próximos encontros. O tema do alcoolismo se destacou como o mais importante ao longo dos encontros. Eles nos apresentaram uma demanda de auxílio no que diz respeito ao alcoolismo, além de pedirem um espaço para que pudessem refletir sobre erros que cometem sem terem consciência.

Outro tema que foi trazido com bastante ênfase foi a importância da instituição Nosso Lar, que representa um local de refúgio, de convivência e de reflexão sobre a própria vida, conforme se percebe na seguintes fala:"Sou liberto do álcool porque tive ajuda dessa casa aqui”.

Os encontros possibilitaram a troca de experiências ente eles, um torna-se o agente terapêutico do outro. De acordo com Moreno (1959), um dos fatores responsáveis pela eficácia de um trabalho em grupo é o fato de que os membros podem ser agentes terapêuticos um do outro, ou seja, o potencial terapêutico não se realiza somente nas intervenções do coordenador do grupo. A troca de experiências entre os componentes do grupo pode levá-los a uma experiência na qual um aprende com o outro e cada membro do grupo não se percebe isolado em sua problemática.

O nosso trabalho tem como foco intervenções que proporcionem um crescente processo de responsabilização por parte dos usuários. Como já foi dito anteriormente, estes sujeitos recebem benefícios de práticas assistencialistas que, de acordo com Brito (2006), culminam por manter este público em uma situação de assujeitamento e humilhação. O nosso projeto tem como objetivo romper com este tipo de prática com o intuito de promover um espaço para a responsabilização dos sujeitos pela própria vida. Entendemos que esta população vive em condições de risco social, mas a nossa intenção é levá-los a refletir sobre o que podem fazer dentro das suas condições. Alguns resultados já podem ser observados neste sentido, conforme é demonstrado pelas seguintes falas: "Não vou desistir. Vou correr atrás e arrumar um serviço”; É preciso ter calma ir devagar em cima do problema, iniciativa para resolver seus problemas... não esperar cair do céu...”

A reflexão "não esperar cair do céu” foi bastante recorrente no grupo. Em alguns encontros os membros do grupo dizem que não se pode ficar esperando a ajuda de Deus 
sem que cada um faça a sua parte, que cada um tome a iniciativa de melhorar a própria vida.

Constatamos, também, a grande indiferença do Estado em relação à população de rua, que não aparece como uma prioridade das políticas públicas, refletindo a situação de invisibilidade que os moradores de rua se encontram. Eles não têm acesso a programas de transferência de renda, porque é exigida a residência fixa nestes casos. Essa omissão dos governos em relação ao morador de rua demonstra que eles representam o "lixo” urbano contemporâneo.

\section{REFERÊNCIAS}

ALVAREZ, Aparecida Magali de Souza; ALVARENGA, Augusta Thereza de; FIEDLER-FERRARA, Nelson. $\mathbf{O}$ encontro transformador em moradores de rua na cidade de São Paulo. Psicol. Soc., Porto Alegre, v. 16, n. 3, 2004.

BRITO, Maria Mercedes Merry. A abordagem e a clínica no atendimento aos moradores de rua portadores de sofrimento psíquico. Psicol. cienc. prof. [online]. jun. 2006, vol.26, no.2, p.320-327. Disponível na World Wide Web: <http://pepsic.bvspsi.org.br/scielo.php

MENDES, Aline Aguiar \& MACHADO, Maria Fernanda. Uma clínica para o atendimento a moradores de rua: direitos humanos e composição do sujeito. Revista Psicologia: Ciência e Profissão. Set 2004, vol 24, no 03.

MORENO, Jacob Levy. Psicodrama. São Paulo: Cultrix, 1975.

MORENO, Jacob Levy. Psicoterapia de Grupo e Psicodrama. São Paulo: Mestre Jou, 1959.

NAFFAH-NETO, Alfredo. Psicodrama: descolonizando o imaginário. São Paulo: Plexus Editora, 1997. 
VARANDA, Walter; ADORNO, Rubens de Camargo Ferreira. Descartáveis urbanos: discutindo a complexidade da população de rua e o desafio para políticas de saúde. Saude soc., São Paulo, v. 13, n. 1, abr. 2004.

VIEIRA, Érico Douglas. Psicodrama: Introdução à Teoria, Prática e Pesquisa. Revista da Sociedade de Psicologia do Triângulo Mineiro, v. 13, n. 1, jan/jun. 2009. 